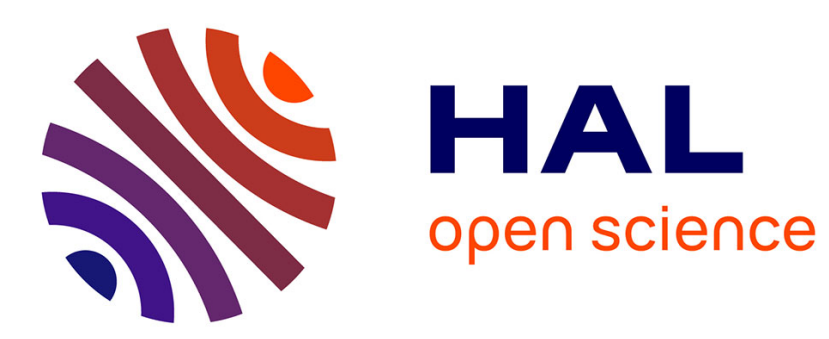

\title{
Modular modeling of maintenance activities for multi-sites structure
}

\author{
Ahmad Alali Alhouaij, Zineb Simeu-Abazi
}

\section{To cite this version:}

Ahmad Alali Alhouaij, Zineb Simeu-Abazi. Modular modeling of maintenance activities for multisites structure. IFAC-IMS Intelligent Manufacturing Systems, Oct 2008, Szczecin, Poland. pp.100. hal-00381189

\section{HAL Id: hal-00381189 \\ https://hal.science/hal-00381189}

Submitted on 5 May 2009

HAL is a multi-disciplinary open access archive for the deposit and dissemination of scientific research documents, whether they are published or not. The documents may come from teaching and research institutions in France or abroad, or from public or private research centers.
L'archive ouverte pluridisciplinaire HAL, est destinée au dépôt et à la diffusion de documents scientifiques de niveau recherche, publiés ou non, émanant des établissements d'enseignement et de recherche français ou étrangers, des laboratoires publics ou privés. 


\title{
MODULAR MODELING OF MAINTENANCE ACTIVITIES FOR MULTI-SITES STRUCTURE
}

\author{
Ahmad ALALI ALHOUAIJ, Zineb SIMEU-ABAZI \\ Laboratoire G-SCOP \\ 46 avenue Félix Viallet \\ 38031 Grenoble cedex 1 \\ Ahmad.ALALI-ALHOUAIJ@g-scop.inpg.fr, zineb.simeu-abazi@g-scop.inpg.fr
}

\begin{abstract}
This paper concerns the modelling of maintenance activities in a distributed context. In this work we study the particular case where the maintenance activities are executed by two workshops: a central maintenance workshop (CMW) and a mobile maintenance workshop (MMW). The (CMW) concerns the repairing process for the corrective maintenance and the (MMW) execute all preventive maintenance in several sites according to a defined scheduling. The aim is to take in account the resources (spare parts in the (MMW) and maintenance actions for a given operating budget. A modular approach for modelling a multi-site structure is proposed to achieve the aim of improving the availability of production sites while minimizing the cost of maintenance. Copyright (c) 2008 IFAC
\end{abstract}

Keywords: Distributed maintenance, Modelling, Petri Stochastic Nets (SPNs), Availability, Scheduling, Cost.

\section{INTRODUCTION}

The concept of Maintenance Workshop has developed in the sectors of activities where the availability of equipment is really important. A maintenance workshop (MW) supports not only the equipment repairing but also the preventive maintenance activities which related with the inspection and changing. In the distributed context, this workshop (MW) can be used to maintain equipment from different production sites. To reduce the failures occurrence, the (MW) must manage resources (operators, tools and spare parts), achieving the real-time of the equipment status in different sites and preventive maintenance activities plan. To improve the availability of production equipment and minimize maintenance costs it is necessary to determine the resources and wellplanned preventive actions.

The resources determination related with the management of maintenance team as far as the tools and spare parts. To achieve the preventive action it is necessary to set a robust schedule, capable of absorbing the operating hazards and having a good security level.
In this distributed context, the maintenance activities are divided on these two following structures:

- Central (CMW) which realizes the process of reparation - corrective maintenance;

- Mobile (MMW) which carries out inspections and replacement on the various production sites.

Fig. 1. illustrates the context of the study and highlights the relationship between the various sites [Simeu-Abazi, 2007].

As a result, this distributed context requires the development of new modelling techniques and scheduling maintenance tasks. The simulation models can take into account the interactions between different sites and determine the resources. More oriented research in the marine field focused on optimizing the availability of merchant ships by proposing the determination of spare parts with a limited cost investment [Rustenburg, 2000], [Lau et al. , 2006], [Keizers et al., 2001]. Others concern in spare parts determination in space [Caggiano and Muckstadt, 2000]. 
A methodological approach on the implementation maintenance which is centralized at the production systems has been developed recently. It relates more particularly with the design of a maintenance workshop within an integrated production system [Abbou, 2003], [Abbou et al., 2004]. The (MW) is then integrated and dedicated to the maintenance of certain and specific equipment which includes repairing several phases (diagnosis, disassembly, repair itself depending on the type of failure, assembly and test).

This paper focuses particularly in cases where one has a Central (CMW) and Mobile (MMW) that can involve making replacements at several sites according to a predefined scheduling. It is a question of dimensioning the various resources (spare parts in the Central or Mobile (MW) and the maintenance team). A modular approach for modelling of a multisite structure is proposed. The aim is to minimize the average cost by applying an appropriate inspection policy for the mobile workshop (MMW).

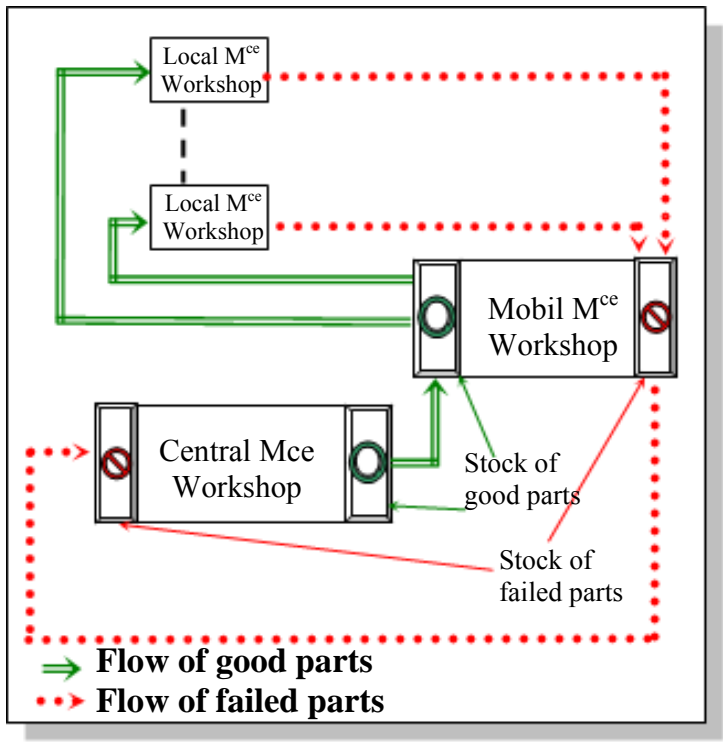

Fig. 1. Relations between the different production sites and maintenance workshops.

After a brief presentation of the framework, the chosen modelling tool (Petri Nets) is presented. For proposing a case study, a model of maintenance workshops (central and mobile) is proposed and illustrated with some simulation results. Some perspectives on the directions of this work will be at the end of this article.

\section{MODELING TOOL}

Petri Nets are tools well appropriate to modelling and analysis of complex discrete events systems by introducing the competition and the synchronization. They were introduced by Carl Adam Petri in 1962 to describe the overall behaviour of complex systems and to carry out the qualitative analysis.

A (PNs) is composed of:
- An assembly seats which is representing various states of the system (represented by circles).

- A set of transitions explain the possibility of system state change (represented by rectangles).

- A series of oriented arcs link between places and transitions.

- Marks (or chips) are represented as black dots in places of constituent's network.

This tool has very descriptive power to represent and analyze the manners and behaviour of complex system, including the phenomena of synchronisation, parallelism, competition or the sharing of resources.

Later in 1978, Stochastic Petri Nets (SPNs) were introduced [Natkin, 80] and [Molloy, 81]. They can calculate probabilities and statistics, and taking into account random events as the occurrence of failures. Taking the immediate transitions (unstable transitions) and the transitions stochastic (stable or delayed), has identified an extension of the (SPNs) which is called Generalized SPNs (GSPNs).

Several modules (PNs) can be synchronized by external events. This dependence is achieved through the linkage between the various modules, which determine the transition firing. This is the global notion of Synchronized PNs (SyPNs) [Moalla, 78]. In this article we have extended the concept of Synchronization events with other events from both the outside and inside the system. In this case it is called the Internal SyPNs (GS $\left.{ }^{2} \mathrm{PNs}\right)$.

\section{APPLICATION OF DISTRIBUTED CONTEXT}

The objective is to propose an approach to modeling and performance evaluation of many of production sites with taking into account the interactions between these sites. The expected performance is more related with improving the availability of production sites, minimizing the number of failures and minimizing maintenance costs.

Taking into account the corrective actions is made through using Stochastic Petri Nets (SPNs). They can model systems subjected to random parameters such as failure or repairs. To take into account the preventive actions, the Generalised SPNs (GSPNs) are used. Indeed, it is necessary to take into account the immediate transitions (unstable) where the staying time is deemed null (Zero) and stochastic transitions (stable or delayed). When marking valid at the time of immediate transitions and delayed transitions, priority is given to immediate crossings transitions. Exchanges between the different sites (production and maintenance) are achieved through signals synchronization. We use this case the GSPNs with Internal Synchronization where the different modules are synchronized by external or internal events.

The tool GS ${ }^{2} \mathrm{PNs}$ is well adapted to the distributed context. The decomposition of the complete system in different module, allows a modular analysis for our system. It is a way we propose a representation 
and a hierarchical analysis of the system which is decomposed as follows:

1. A generic model which represents the production sites $\mathrm{SP}_{i}(i$ : number of the site).

2. A generic model which represents the central maintenance workshop (CMW).

3. A model representing the mobile maintenance workshop with the associated routing (MMW).

4. A generic model of the stock of the mobile maintenance workshop (MMW).

Table 1 lists the various data which are used in the proposed models and their objectives.

\begin{tabular}{||c|c|c||}
\hline $\begin{array}{c}\text { Type } \\
\text { of } \\
\text { System }\end{array}$ & Data & Objectives \\
\hline CMW & $\begin{array}{c}\text {-The arrival rate of these } \\
\text { faulty parts. } \\
\text { - Tasks Characteristics. }\end{array}$ & $\begin{array}{c}\text { - Average time means of } \\
\text { minimum staying } \\
\text { - Size of the repaired } \\
\text { stocks }\end{array}$ \\
\hline $\mathbf{M M W}$ & $\begin{array}{c}\text { - Storage capacity : }(\eta) \\
\text { - Distances between } \\
\text { production sites : } \\
\left(\mathrm{d}_{\mathrm{i}, \mathrm{i}+1}\right)\end{array}$ & $\begin{array}{c}\text { - Scheduling tasks } \\
\text { - Determination of } \\
\text { resources operators and } \\
\text { equipment } \\
\left(\tau_{\mathrm{p}}\right)\end{array}$ \\
\hline $\mathbf{S P}$ & $\begin{array}{c}\text { - equipment references } \\
- \text { Distance of the CMW: } \\
\left(\mathrm{d}_{0 \mathrm{i}}\right)\end{array}$ & Time of replacement \\
\hline \hline
\end{tabular}

Table 1 - Summary data and targets for each type of workshop

\section{MODULAR MODELING: PRINCIPLE}

The decomposition of the system in several modules makes them better and simple in the analysis phase. It is supported by $\mathrm{GS}^{2} \mathrm{PNs}$.

To obtain the model of the whole system from different modules it is necessary to follow these steps: [SASSINE Ch, 1998] :

1. Make a structural division of the system: a system of (n) production sites can be decomposed (n) cells.

2. A generic model is associated with each cell using $\mathrm{GS}^{2} \mathrm{PNs}$.

At each cell, synchronization signals are generated: places where they are active send signals that determine the transitions that receive them.

\section{ASSUMPTIONS (HYPOTHESES)}

Our work focuses on the application of centralized maintenance of multi-site production workshop which include a central (CMW), several production sites and a (MMW). To evaluate the performance of this complex system, we made some assumptions.

\subsection{Assumptions on production sites.}

1. All $\mathrm{SP}_{i}$ are identical, using equipments with identical characteristics.
2. No resources are shared between production and maintenance sites.

3. If the equipment is failed, the production in the site is stopped.

4. The preventive maintenance (PM) is executed only if SP in the rest state and at the date of predefined occurrence of a PM. (Preventive Systematic maintenance).

\subsection{Assumptions on the Central MW.}

1. The failed equipment is repaired with the time duration corresponding to the average repairing rate $(\mu)$.

2. In the (CMW), there is always a sufficient stock of the repaired parts that are ready to be loaded.

\subsection{Assumptions on the Mobile MW.}

1. At each site, there is only a standard replacement for one single type of part.

2. When the number of parts in stock is higher than the security stock level, mobile MW continued its scheduled maintenance operation.

3. When the number of parts in stock is less than or equal to the security stock level, mobile MW follows a predefined scenarios.

4. The staying time at the site is characterized by the average replacement time.

\section{THE GENERIC MODELS}

The multi-site system is composed of various generic models which are based on GS ${ }^{2} \mathrm{PNs}$.

- The production sites $\mathrm{SP}_{i}$ : is a model that must take into account the internal workings of the site i but with also maintenance tasks.

- The central maintenance workshop (CMW) is a model that must take into account the complete process of repairing in addition to the arrival rate of defective parts.

- The mobile workshop (MMW) is a model that must take into account the storage capacity of the (MMW).

- The maintenance policy is a model that must take account of corrective or preventive maintenance tasks.

- The routing is a model that represents the planning of maintenance tasks of the following (MMW) with well defined scenarios.

\subsection{The model of production sites.}

It is a model that represents the various models of production site operation SP. It is synchronized by the scheduled preventive maintenance events (preventive maintenance and presence of (MMW) on the site). 
The GS ${ }^{2}$ PNs of this model (see Fig. 2.), generates all the signals which indicate the site state: in production, failure state and waiting state for preventive maintenance.

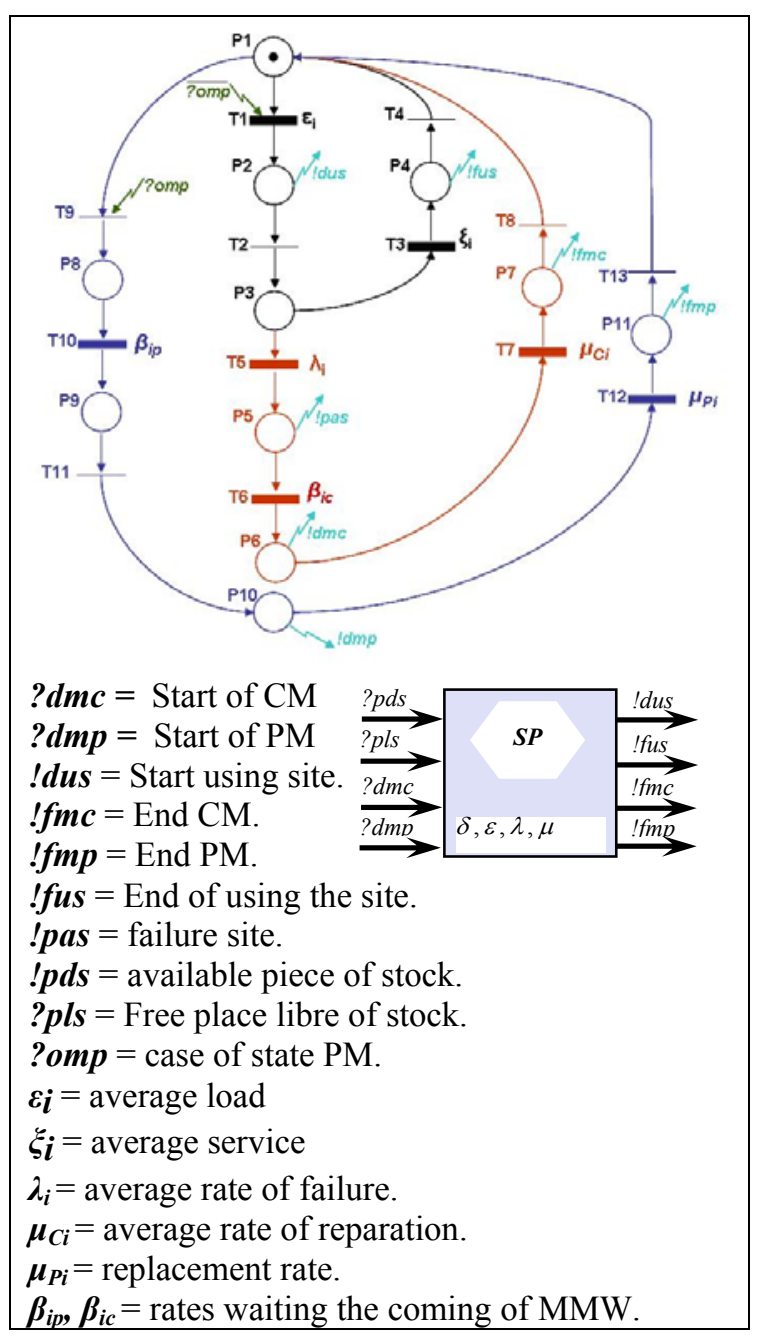

Fig. 2. Model GS ${ }^{2} \mathrm{PN}$ for production Site

The P1 place represents the state rests or the state of SP is ready to start one of its operation modes. If any $\mathrm{PM}$ is programmed, the production operation can be launched (crossing T1) with sending the signal (!dus) corresponding to beginning of production cycle to the place $\mathrm{P} 2$. . The operating state in production mode is represented by the place $\mathrm{P} 3$.

After the average time of service associated to the transition $\mathrm{T} 3$, the system returns to its waiting position through $\mathrm{P} 4$ which sends the signal (!fus) corresponding to the end of the production cycle.

In the case of a date PM, SP stop its production cycles, it will run as PM. The presence of (MMW) allows launching the process of replacing (P10 instead of sending a signal-from beginning PM).

The staying length in this position P10 depends and the replacement average time associated with the transition T12. At the end of replacement a signal is generated by $\mathrm{P} 11$.

An average waiting time $\left(\boldsymbol{\beta}_{\boldsymbol{i c}}\right)$, is associated with the transition T6. It corresponds to the time needed to availability of resources (new parts in (MMW), tools and operators).
Throughout corrective maintenance, beginning signal of the corrective maintenance $(! d m c)$ is transmitted. The duration of the $\mathrm{CM}$ corresponds the repairing average time $\left(\mu_{\mathrm{ci})}\right.$, is associated with T7.

When the time is finished, a signal corresponding to the end of maintenance (!fmc) is sent.

The model for the production site consists of two representing cycles, the different modes of operation of the site:

In the production phase, it is following closed cycle (loop) :

$(\mathrm{P} 1 \rightarrow \mathrm{T} 1 \rightarrow \mathrm{P} 2 \rightarrow \mathrm{T} 2 \rightarrow \mathrm{P} 3 \rightarrow \mathrm{T} 3 \rightarrow \mathrm{P} 4 \rightarrow \mathrm{T} 4 \rightarrow \mathrm{P} 1)$.

In corrective maintenance phase the loop is :

$(\mathrm{P} 3 \rightarrow \mathrm{T} 5 \rightarrow \mathrm{P} 5 \rightarrow \mathrm{T} 6 \rightarrow \mathrm{P} 6 \rightarrow \mathrm{T} 7 \rightarrow \mathrm{P} 7 \rightarrow \mathrm{T} 8 \rightarrow \mathrm{P} 1)$,

In the case of preventive maintenance the loop is : $(\mathrm{T} 9 \rightarrow \mathrm{P} 8 \rightarrow \mathrm{T} 10 \rightarrow \mathrm{P} 9 \rightarrow \mathrm{T} 11 \rightarrow \mathrm{P} 10 \rightarrow \mathrm{T} 12 \rightarrow \mathrm{P} 11 \rightarrow \mathrm{T} 13$ $\rightarrow \mathrm{P} 1)$.

Note1:

It was considered that the failure can happened only during he running, not the state of rest.

Note 2:

Signals the beginning and end of maintenance are used for stock management of (MMW).

\subsection{Model of the CMW.}

The model of (CMW) is detailed in the thesis of ABBOU [Abbou R, 2003]. It consists of several items needed to repair failed equipment

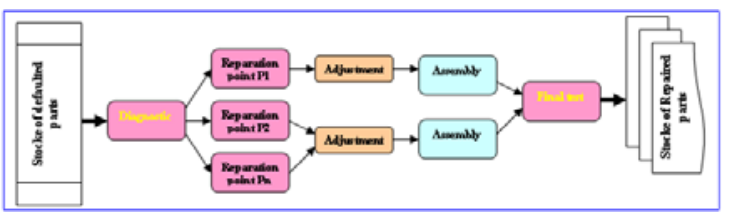

Fig. 3. Module of the central MW

\subsection{The Stock of $M M W$}

It is a model that allows managing the new and failed parts to be presented in the (MMW). It is synchronized with the model representing the policies of this maintenance.

The stock of (MMW) is represented by a $\mathrm{GS}^{2} \mathrm{PNs}$ with two states and two transitions as shown in (Fig. 4.). The place $\mathrm{P} 1$ sends a signal (!pds) which indicates that there is at least one part available in stock. $\eta \mathrm{j}$ is the number of marks in place P1 which represents the maximum capacity of the (MMW) stock. The transition $\mathrm{T} 2$ is conditioned by the beginning of operation of corrective or preventive Maintenance. When T2 is crossed, a new part is gotout from stock and a place is getting free to receive a defective part by sending the signal (!pls) from the place $\mathrm{P} 2$.

When the replacement is finished, depending on whether the maintenance is corrective or preventive, the signals (? fmc or ?fmp) validate the transition $\mathrm{T} 1$. The marking of $\mathrm{P} 1$ represents the number of parts in proper functioning $\left(\mathrm{n}_{\mathrm{b}}\right)$, marking P2 represents the number of defective parts $\left(\mathrm{n}_{\mathrm{d}}\right)$. 


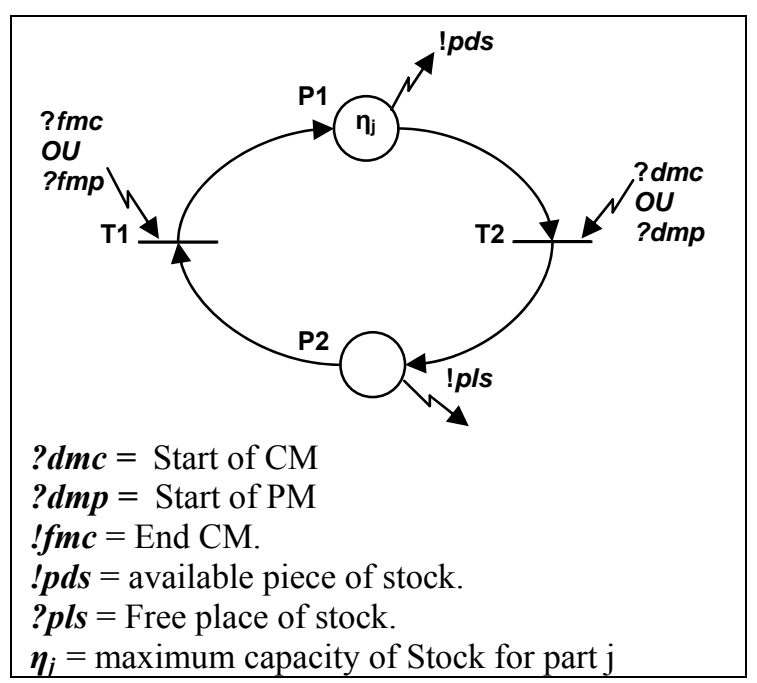

Fig. 4. Module Stock

\section{Note 3:}

The non-appearance of the signal ( $p d s$, available place in stock) reflects the fact that the stock is zero.

Note 4:

Initially $\mathrm{n}_{\mathrm{b}}=\mathrm{n}_{\mathrm{d}}$

\subsection{Maintenance Policies}

The model of PNs consists of two parts, the policy of maintenance corrective CM (CMW), and policy maintenance preventive PM (MMW).

\subsubsection{Model Corrective Maintenance CM.}

It is a model consists of three places and three transitions as shown in Fig. 5. It is synchronized with the random occurrence of a failure issued by the model of the production site and the availability of resources.

P1 represents the state of rest of the maintenance team. The corrective maintenance starts only if there is reported (?pas) and that (MMW) is present on the site (?asp). Note that the signal (pas) contains all the information on the type of failure and associated with SP.

Throughout repair a signal is emitted by the place P2 indicating the beginning of maintenance $(? d m c)$. After an average time of repairing $(\tau c)$ associated with the transition T2, a signal of end of this activity (!fmc, the end of the $\mathrm{CM}$ ) is issued.

\subsubsection{Model Preventive Maintenance PM.}

As a model of corrective maintenance, the model consists of three places and three transitions as it is shown in Fig. 6.

The Model Preventive Maintenance is synchronized with the scheduled case of preventive actions. The place $\mathrm{P} 1$ represents the state rest of the maintenance team. The preventive maintenance doesn't starts up to the date of occurrence of an PM (?omp) according to a predefined planning and if (MMW) is present on the site (?asp).

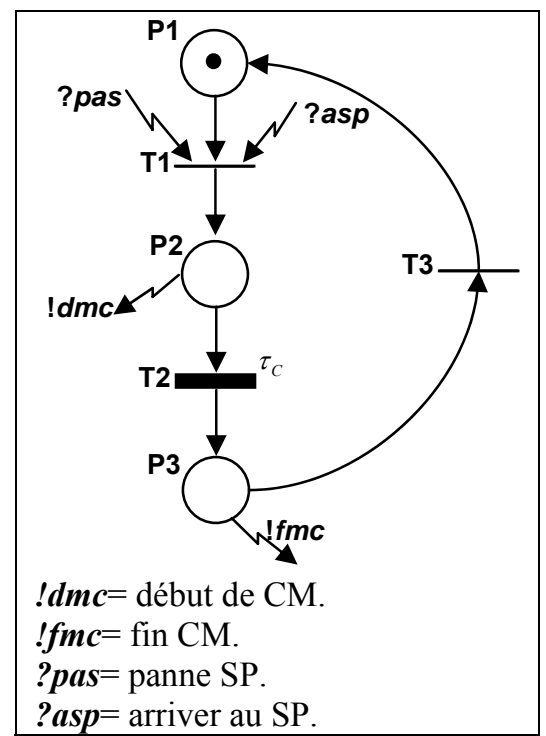

Fig. 5. Module of CM policy

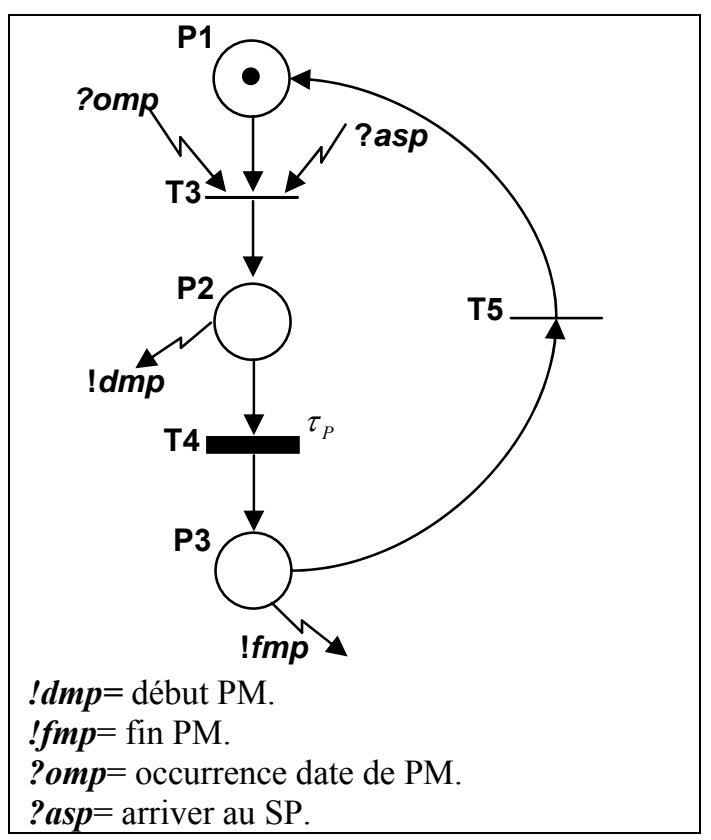

Fig. 6. Module of CM policy

When T3 is reached, the operation of replacement of failed equipment with a new one is launched by sending the signal (?dmp). The average replacement time ( $\tau p)$, is associated with the transition T4. The signal of end of this replacement procedure (!fmp) indicates that the SP has been sent within function of maintenance is available for other maintenance operations.

\subsubsection{Model of overall maintenance.}

To address the problem of conflict which can reach in a case of the preventive maintenance, we offer a single module which includes maintenance models $\mathrm{CM}$ and PM. Whenever the event occurs, the priority is given to corrective maintenance. Therefore, the displacement from (MMW) to SP (failure) has always given priority. 


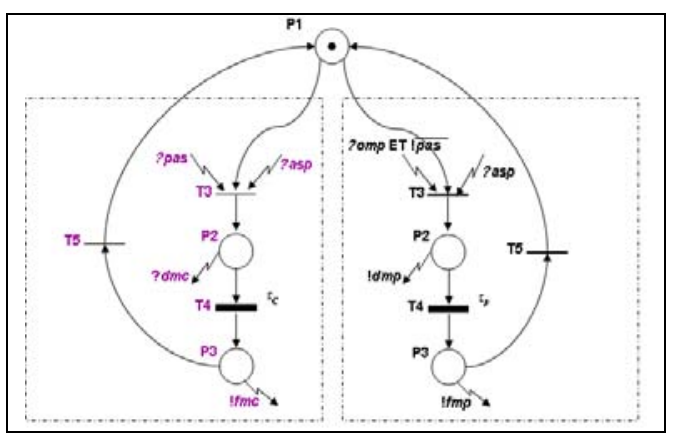

Fig. 7. Model ,GS² PN of Maintenance

Note 5:

In these models we take into account the condition of available part in stock because the displacement of (MMW) to the production site is already conditioned by the presence of non-defective parts.

\section{Note 6:}

At each signal the beginning of maintenance ( $d m c$ or $d m p$ ), a piece of the new parts stock is consumed, and each signal of end of maintenance ( $f m c, f m p$ ) refers that there is a piece in the stock of defective parts is added.

\subsection{Model of routing the $M M W$}

It is a model that represents the sequence of actions of maintenance (corrective or preventive) to be performed by the mobile workshop. It is synchronized with the dates of occurrence of PM, the case of a failure and the level of stock. The parameters are taken into account in the evaluation phase are:

- Distances between the sites

- Storage capacity of the (MMW)

The (MMW) deals with the supply of spare parts (new or repaired) at the (CMW) but also related with different sites for replacement operations. These activities are defined by the following algorithm (Fig. 8.).

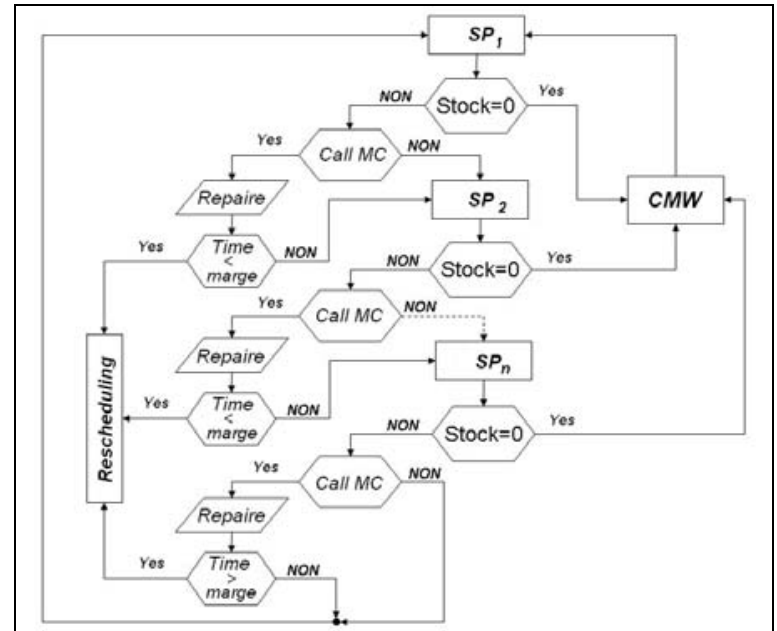

Fig. 8. Flow chart of routing

Note 7:
It is considered here that there is always the number of repaired the stock out of (CMW), it is also sufficient to meet the need for (MMW) (its maximum capacity).

From the Fig. 8. You can save the algorithm following:

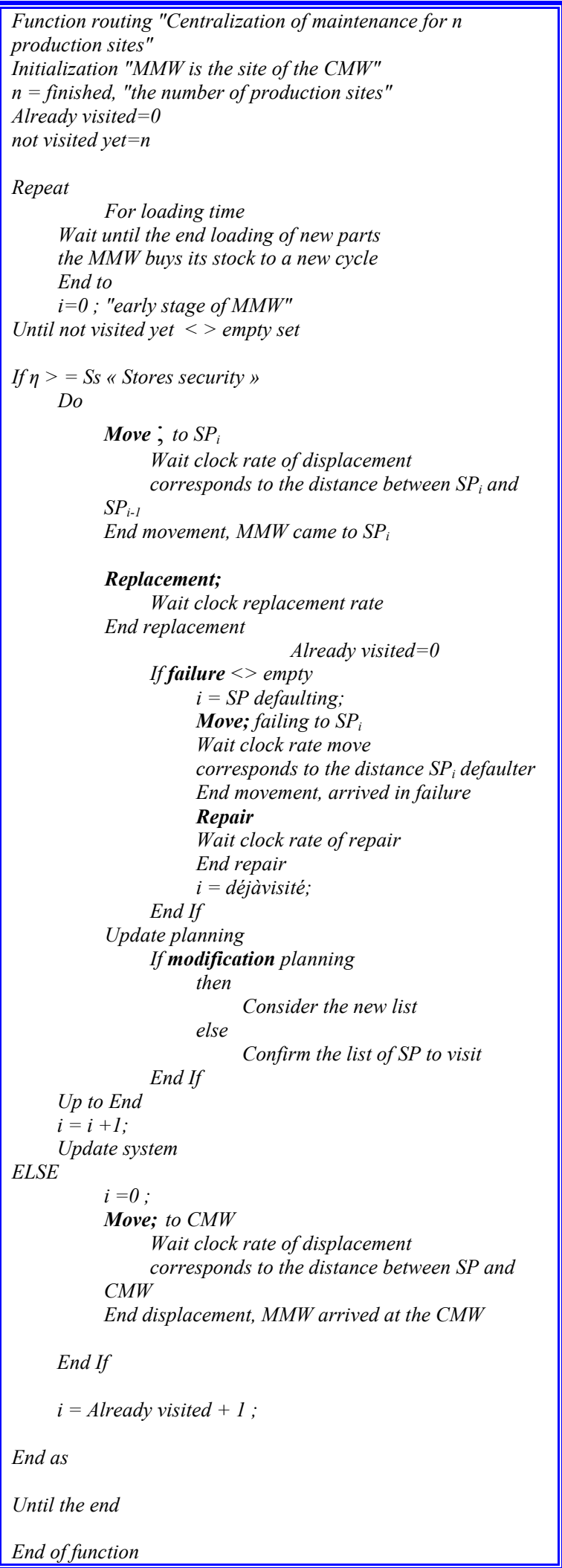

By applying the algorithm above, we obtain the model in Fig. 9. 


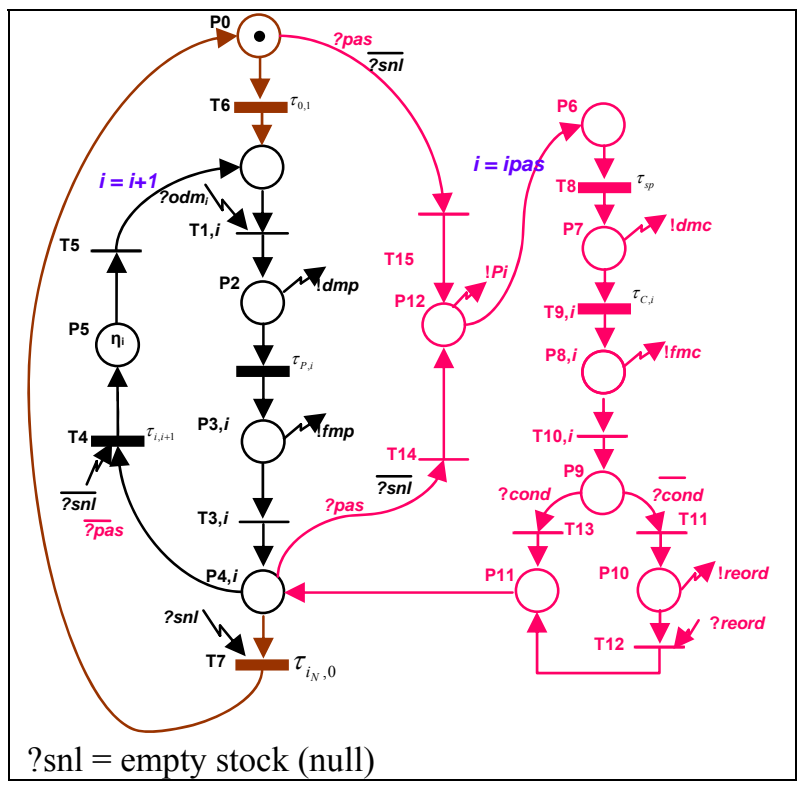

Fig. 9. Module of (MMW) routing

In P0, the (MMW) buys from the (CMW). without failure and if the level of stock exceeds the threshold (safety stock), routing is done according to predefined schedule. The occurrence of a failure is likely to require scheduling tasks.

Moving to production site $\rightarrow$ Replacement of failed parts with new ones $\rightarrow$ In the absence of failure, the moving to the following site if the stock level is higher $\mathrm{Ss} \rightarrow$....

If planning is robust presence from the (MMW) to the SP, it must correspond to the time interval where the SP is in a state of rest.

\section{Note 8:}

Each model PNs may be represented by a black box with input / output of signals associated synchronization and other parameters such as timers, which will be associated with the crossing of transitions.

\section{THE SIMULATION MODELS}

The best tool suited for the simulation of various models proposed is Matlab. Indeed, the toolbox allows State-flow modelling and simulating such complex systems. We will limit the simulation part to a single production site, taking into account its various modes of operation. Thus, the normal operation, stops for corrective maintenance, stops for systematic preventive maintenance are modelled and simulated.

To represent the behavior of the site as well as different modes of operation, it is necessary to build some functions that generate random events as the occurrence of a failure. The occurrence of a failure leads to the stopping of the site awaiting repair. In addition, the duration of repair depends on the failure (we take it as random), a random time is associated with duration of repair (Fig. 10.).

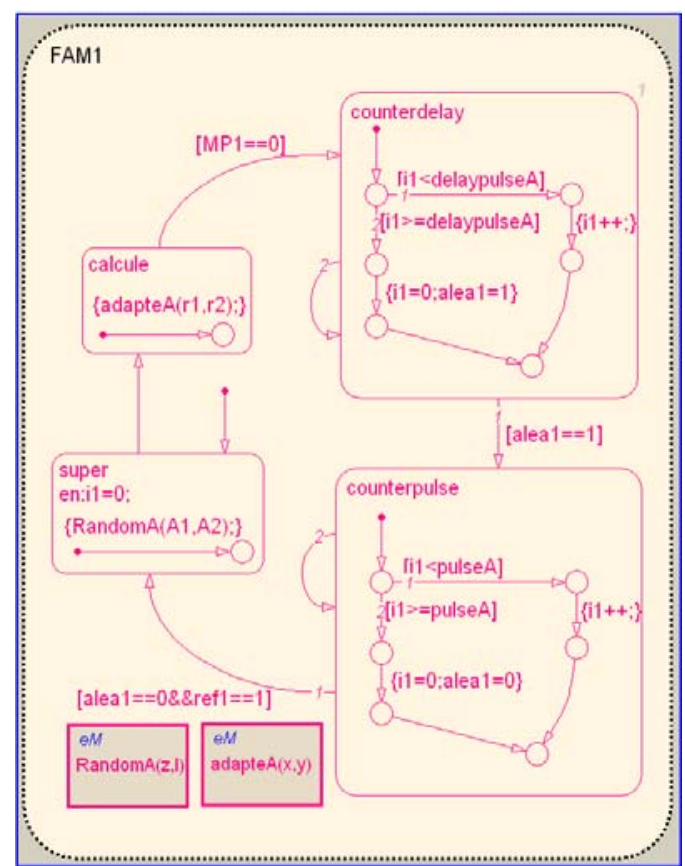

Fig 10. Generation a random function.

(Fig.11.) shows the model Stateflow of random events generator, and Fig. 11. model of a production site. The simulation Stateflow allow calculating the overall cost of maintenance and contributes to determine the storage capacity of the mobile workshop.

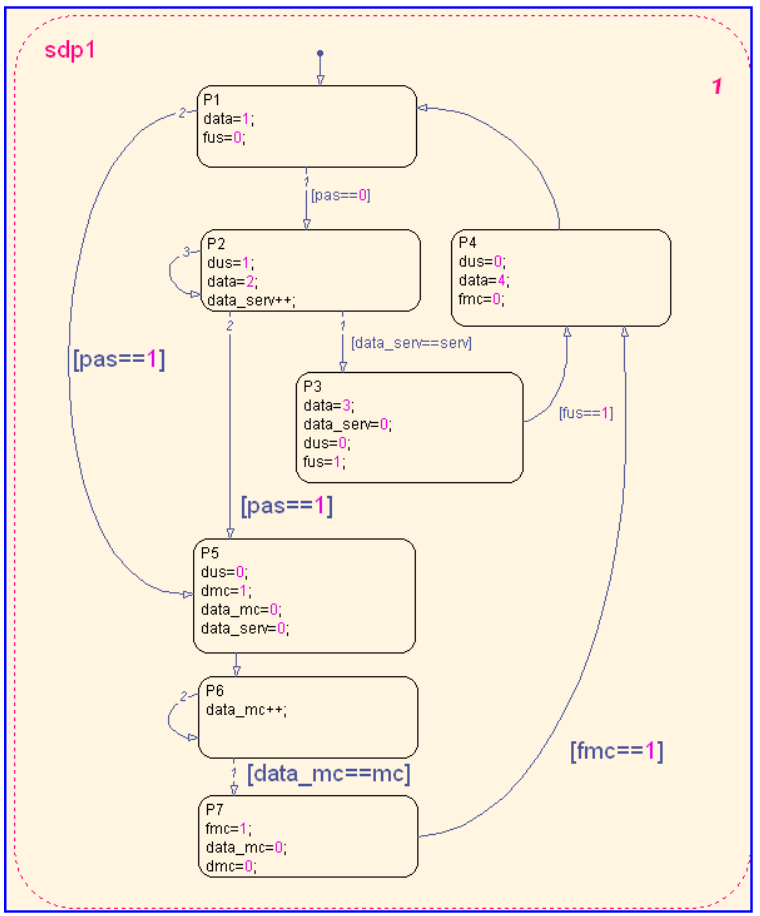

Fig. 11. Simulation Model for the production operation in each SP

\section{CONCLUSION}

In this article, we proposed a model to take into account maintenance operation in the multii-sites context. To simplify the number of constraints to 
consider, the model for this system was built under certain assumptions. The model based on $\mathrm{GS}^{2} \mathrm{PNs}$ can better understand the distributed maintenance process, which is the main theme of this study. The simulation of various workshops synchronized (in progress) can analyse and evaluate the performances of maintenance (failure rate, availability, cost, rate of return synthetic...).

This work opens several perspectives. The first is to remove some of the assumptions in the modelling distributed maintenance system.

In the model proposed a single type of equipment is taken into account at each site (assumption1). This assumption restricts the field of distributed maintenance. It is necessary to take into account the diversity of equipment, and MW must be able to rehabilitate various types of equipment. The proposed generic models can be evolved from GS2PNs to the Colored GS2PNs (Co-GS2PNs). In addition, replacement of equipment can generate substantial costs, and then it is necessary to consider replacement multi-level equipment. In other words, it is important to take into account not only the replacement of the full equipment but only a section of the equipment.

\section{REFERENCES}

Abbou R, 2003. Contribution à la mise en auvre d'une maintenance centralisée: conception et optimisation d'un atelier de maintenance. Thèse de Doctorat, Université Joseph Fourier, Grenoble, France.

Abbou R., Z. Simeu-Abazi, M. Di Mascolo, 2004. Atelier de maintenance intégré dans un système de production: conception et évaluation des performances. Journal Européen des Systèmes Automatisés, Vol. 38 n¹-2, pp. 197-223.

ALALI ALHOUAIJ A. , SIMEU-ABAZI Z. , ALLA H, 2006. Ordonnancement Robuste des Tâches de Maintenance Préventive. MMR'06, Rabat, Maroc.

Caggiano K. E., J. A.Muckstadt, 2000 Maintenance Support for the Reusable Launch Vehicle Program: Determining and Evaluating Spare Stock Levels for Recoverable Parts, Technical report $n^{\circ} 1269$, School of Operations research and industrial engineering, Cornell University, Ithaca, NY 14853.

MOLLOY M.K., 1981. On the integration of delay and throughput measures in processing models. Thèse de doctorat, university of California, Los Angeles, USA.

Naktin S., 1980. Les réseaux de Petri Stochastiques. Thèse de Doctorat, CNAM, Paris, France.

Pham D.M, 2005. Application de la maintenance centralisée pour les systèmes de production multi-sites. Rapport de master AutomatiqueProductique, de l'INPG, Grenoble, France.
Rustenburg J., 2000. A system approach to budgetconstrained spare parts management, Thèse de doctorat, Eindhoven University of Technology, Pays Bas.

SASSINE Ch., Simeu-abazi Z., 1998. Intégration des politiques de maintenance dans les systèmes de production manufacturiers. Thèse de Doctorat, INPG, Grenoble, France.

Simeu-Abazi Z., 2007. Maintenance centralisée pour les systèmes de production multi-sites, RFGI, revu française de gestion industrielle, vol. $\mathbf{n}^{\circ} \mathbf{2 6}$.

Daniel, Simeu-Abazi Z. and Descotes-Genon, 1994. A new tool : the Generalised and Synchronised Stochastic Petri Nets, IMSE 94 IFAC - INRIA.

Simeu-Abazi Z., Zikmund J. and Bouredji Z., monitoring and predictive maintenance : optimisation of fault latency. Laboratoire d'Automatique de Grenoble (CNRS, INPG, UJF) L.A.G / E.N.S.I.E.G, Saint Martin d'Hères, France.

DAVID R. and ALLA H., 1994. Petri Nets for Modeling of Dynamic Systems - A Survey Automatica. vol.30, $\mathrm{N}^{\circ} .2$ pp 175-202.

S. Marier, A. El Mhamedi and Z. Binder, 1994. Modélisation \& évaluation d'une mission de téléopération par RdP Stochastique Généralisé. RAPA, vol.7, N³, PP 317-337.

D. Chevron, Ch. Sassine and Z. Binder, 1997. Modeling and Maintenance of Semi-Automated Disassembly Cell by Petri Nets. ECC ' 97 belgium, vol.2 , pp FR-A K3.

Simeu-Abazi, Lung L., 2000. Maintenance in the manufacturing systems. AP 00-048.

[1] ALALI ALHOUAIJ A. , SIMEU-ABAZI Z. , 2008. Modélisation modulaire des activités de maintenance dans une structure Multi-sites. MOSIM'08, Paris, France, pp221, vol.1. 